\title{
Research on C2C Logistics Distribution Network Planning
}

Tan Yongbin ${ }^{1, a}$, Zhang Qingying ${ }^{2, b}$, Chen Yang ${ }^{3, c}$

${ }^{1}$ Institute of Logistics Engineering, Wuhan University of Technology, Wuhan, 430063, China

${ }^{2}$ Institute of Logistics Engineering, Wuhan University of Technology, Wuhan, 430063, China

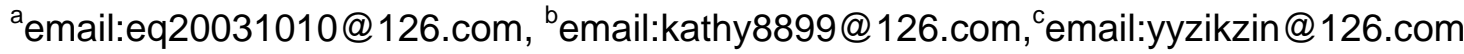

Keywords: C2C e-commerce, mass logistics, distribution network planning

\begin{abstract}
In recent years, with the rapid development of the e-commerce, C2C (Consumer to Consumer) as a kind of the transactions on the Internet named "private to private" will become the main force for the future development of the e-commerce. This paper analyzed the significance of mass logistics distribution, discussed the main parts of distribution network planning and made suggestions for C2C logistics distribution network planning.
\end{abstract}

\section{Introduction}

In recent years, with the rapid development of network technology, online shopping become a new online transaction mode. At present, C2C e-commerce in China is developing rapidly. Research on the logistics mode of $\mathrm{C} 2 \mathrm{C}$ e-commerce, can not only find out the problems of the logistics distribution of e-commerce, promoting the development of e-commerce, but also can provide reference for China's third party logistics enterprise to promote their service quality[1].

In this paper, combined with the "mess logistics theory" and "logistics distribution network planning theory", a new logistics distribution mode has been put forward. C2C mess logistics distribution mode means that the e-commerce platform to establish public logistics center, which manage the warehousing and transportation of goods for the e-commerce enterprises. The third party logistics enterprises responsible for distribution of goods[2]. What's more, this paper analyze the main parts of $\mathrm{C} 2 \mathrm{C}$ mass logistics distribution network planning and made some suggestions.

\section{The significance of C2C mass logistics distribution}

C2C e-commerce logistics model is a new mode of logistics which is based on the modern logistics theory for making the C2C e-commerce logistics more efficient, fast and lower cost. It integrates business e-commerce platform, e-commerce enterprise and third party logistics and other aspects of resources[3]. According to the distribution of the net buyers, layout the entire warehouse outlets comprehensively, the public logistics centers are established by e-commerce platform, e-commerce enterprises manage the warehousing and transportation in the public logistics center, the third party logistics is responsible for the local distribution.

C2C mass logistics mode means that e-commerce platform establish the public logistics centers, e-commerce enterprise centralized goods to storage and transport, the third party logistics enterprise in charge of local distribution[4]. The seller can send their goods in batches to the corresponding logistics center, when the seller receives orders from the buyer, seller can sent the orders to the public logistics center online[5]. After the public logistics center receive orders, goods will be sent to the buyer's city, the third party logistics enterprises distribute goods. C2C mass logistics mode as shown in figure 1-1. 


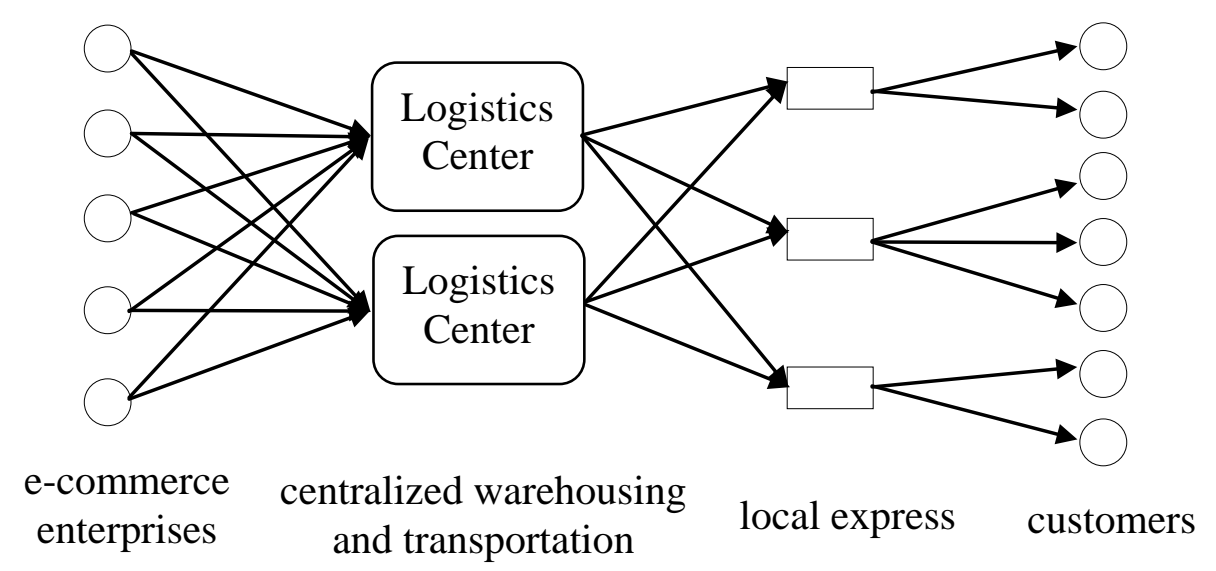

Figure 1-1 C2C mass logistics mode

The establishment of the public logistics center, function and significance of centralized warehousing and distribution:

(1) To overcome the limitations of the existing distribution model

In the part of distribution efficiency, the establishment of logistics Center changed the distribution of seller's goods, centralize seller's goods can shorten distribution distance between buyers and goods. The logistics center distribute the goods to the buyers of same regional at the same time, the formation of large batches and small quantities in the form of intercity transportation. Shorten the transportation distance and reduce the frequency of transport, which can not only improve the efficiency of logistics and distribution, but also reduce logistics costs effectively.

(2) Saving distribution costs

In the part of transportation costs, C2C distribution model allows single orders despite the transport process from one time becomes twice, the distribution process seem to become complicate. Actually, less than container load(LCL) logistics converted to twice full container load logistics(FCL), sellers transport the goods to all the logistics centers, and then transport from the logistics center to the buyers. Because the cost of FCL logistics less than the cost of LCL logistics, this distribution model can greatly reduce logistics costs.

In summary, C2C e-commerce platform have logistics centers, e-commerce enterprise centralize warehousing and distribution is necessary. That not only can help the seller to reduce costs, third-party logistics companies to ease pressure on the stock, but also bring convenience for buyers, as well as help to further expand the scale of the C2C enterprise itself to obtain a broader market.

\section{The main parts of C2C mass logistics distribution network planning}

The main distribution network planning is the use of mathematical methods to plan distribution center location, route optimization and the mount of vehicles. Based on ensuring customer service levels, to minimize distribution costs of goods in the distribution process. Distribution network planning main parts are:

(1) The distribution network structure

Distribution network structure refers to the transfer of goods from the production area to the space consumption of the region in the process of moving (transporting) and stationary (Cargo transiting, dressing up, sorting, warehousing, packaging, etc.) control strategy and organization. Different functions, and its facilities are also there must be some difference. In the requirements of distribution center location, the higher the level of the node, the more transit task and transportation distance. Different transportation is necessary in different level. Thus, higher level node is closer to the transportation hub. The lowest node is mainly responsible for the cycle of inventory and transport equipment. The nodes are usually plays the role of connecting different modes of transportation.

(2) The distribution facility location

Distribution facility location problem is considered within a specified or indefinite area, the 
demand at each point has given, choose the best number and position of the distribution facilities to make the operating costs of distribution facilities and transportation costs fall to a minimum. Location decision involve very much factors. Transport costs and efficiency are main factors in the location decision of distribution facilities. If each candidate points geography, market conditions and other non-cost factors that difference is very small, the location decision can be mainly determined by transportation costs and operating costs.

(4) The distribution lines optimization

Distribution which usually service a large number of users, suitable for small batches, multi-species transportation of goods. The route is short but complicate. The trucks back and forth many times and have a fixed line. One time have a low saving, but distribution have many times, the total cost can be reduced. Planning distribution routes can reduce the cost of transportation effectively. It must be based on a comprehensive plan to develop an efficient transportation routes. Reasonably determine delivery routes is to use the least amount of capacity, taking the shortest mileage, spend the least cost, the least part, with the fastest speed transport the goods to the user.

(5) The transportation optimization

The transportation optimization include transport optimization and optimization of goods loading. The goods often species categorized into specified location in the distribution center., Distribution centers often combine different users on a cargo shipping route in order to taking full advantage of the capacity and improve transport efficiency. It can reduce the shipping costs and reduce the traffic flow. Therefore, it is necessary to sort and load the goods in distribution.

\section{The optimization strategies of C2C mass logistics network planning}

C2C mass logistics network planning the biggest advantage is that concentrated flow of goods, lower the unit cost of transportation between logistics center and customers. This paper presents some of the following suggestions..

Firstly, plan distribution network rationally. Public logistics centers are established in the area which have many customers to improve the regional distribution network system by referring centralized distribution network planning ideas. Increasing investment in infrastructure and introducing of foreign advanced equipment and technology appropriately to improve the efficiency of public distribution centers.

Secondly, select the best third-party logistics service providers. Sellers can select the best logistics service providers by themselves. Third-party logistics service providers are managed dynamically which formulate the evaluation criteria for them and adjusted based on the evaluation criteria dynamically. The dynamic management help the distribution companies enhance their service awareness, improving their service quality.

Lastly, improve the logistics information platform. The country's logistics centers and the third party logistics enterprises are closely linked by fast, convenient information technology, which strengthen contact between the logistics center and third party logistics enterprises. Establish logistics supply chain service, integrated distribution services, strengthen supply chain management.

\section{Conclusion}

This paper discusses the significance of centralized warehousing and distribution, put forward C2C mass logistics distribution mode. Through the analysis of the distribution network planning,

the distribution network structure and network distribution location is very important can be concluded and make some suggestions. C2C e-commerce is still in the stage of development, its maturity and development needs the industry of C2C to joint efforts.

\section{References}

[1] Ramanathan, Ramakrishnan. The moderating roles of risk and efficiency on the relationship 
between logistics performance and customer loyalty in e-commerce[J]. Transportation Research Part E, 2010, 46(6): 950-962.

[2] Yaobin Lu. From virtual community members to C2C e-commerce buyers: Trust in virtual communities and its effect on consumers' purchase intention[J]. Electronic Commerce Research and Applications, 2010(9): 346-360.

[3] Elliot Rabinovich, A. Michael Kneneyer. Why do internet commerce firms incorporate logistics service provides in their distribution channels The role of transaction costs and network strength Journal of Operations Management, 2007, 25(3): 661-681.

[4] Sutanonpaiboon, Abuhamdieh. Factors Influencing Trust in Online Consumer-to-Consumer (C2C) Transactions[J]. Journal of Internet Commerce, 2008, 7(2): 203-219.

[5] H. C. W. Lau. A credibility-based fuzzy location model with Hurwicz criteria for the design of distribution systems in B2C e-commerce[J]. Computers and Industrial Engineering, 2010, 59(4): 873-886. 